\title{
Fatty Amides in Minutes: Direct Formation from Fatty Esters in a Green Synthetic Process
}

\author{
Onyanobi Abel-Anyebe ${ }^{1,4,}$, , Nabil Idris ${ }^{2}$, Djene Keita ${ }^{4}$, Kieran Ita Ekpenyong ${ }^{3}$, \\ Momoh Audu Yakubu ${ }^{4}$ \\ ${ }^{1}$ Science Laboratory Technology Department, Benue State Polytechnic, Ugbokolo, Nigeria \\ ${ }^{2}$ Chemistry Department, Howard University, Washington DC, The United States \\ ${ }^{3}$ Chemistry Department, University of Jos, Jos, Nigeria \\ ${ }^{4}$ Department of Environmental and Interdisciplinary Sciences, Texas Southern University, Houston, The United States
}

Email address:

onyanobi.abel-anyebe 9 tsu.edu (O. Abel-Anyebe)

${ }^{*}$ Corresponding author

\section{To cite this article:}

Onyanobi Abel-Anyebe, Nabil Idris, Djene Keita, Kieran Ita Ekpenyong, Momoh Audu Yakubu. Fatty Amides in Minutes: Direct Formation from Fatty Esters in a Green Synthetic Process. Science Journal of Analytical Chemistry. Vol. 8, No. 1, 2020, pp. 18-28. doi: $10.11648 /$ j.sjac.20200801.14

Received: July 25, 2019; Accepted: August 20, 2019; Published: February 13, 2020

\begin{abstract}
Fatty amides are used in the manufacture of drugs, cosmetics, plastics, insecticides, etc. but the synthetic process involves fatty ester-derived fatty acid steps with economic and environmental consequences. Fatty esters (vegetable oils) are available in abundance and renewable but have not been used directly or cost effectively in the production of fatty amides. The fatty ester is usually first stripped to fatty acids resulting in a two-step instead of a single step synthesis which requires high temperatures $\left(100-240^{\circ} \mathrm{C}\right)$, long reaction time $(3-72$ hours) and the use of catalyst. We had previously reported on a novel green method for the direct formation of fatty amides from a fatty ester. In the present study, the functionality and applicability of this green method is evaluated using a culinary and non-culinary oil namely peanut and castor oils. Each oil sample was hydrolyzed with $\mathrm{NaOH}$ in a non-aqueous medium and reacted in-situ with $\mathrm{NH}_{4} \mathrm{Cl}$ at $50^{\circ} \mathrm{C}$ in a reaction time of 60 minutes with no catalyst added. Conversions of 83 and $79 \%$ were recorded for the reactions of peanut and castor oils, respectively. The products of synthesis were characterized by Fourier-transform infrared spectroscopy (FT-IR) and various concentrations of product samples and two reference samples - erucamide and oleamide obtained from Sigma Aldrich - were subjected to Gas chromatography - Mass spectrometry (GC/MS) analysis. The qualitative GC-MS reports revealed the presence of 9octadecenamide (oleamide) and hexadecanamide (palmitamide) at retention times of 27.76 and 23.90 minutes, respectively for all samples, including the reference. The predominant component of the second reference sample, erucamide, was found to be 13-docosenamide (erucamide) appearing at GC retention time of 32.58 minutes. The IR spectra of the products are strongly indicative of the presence of amides. The GC-MS analysis of the product samples confirms the formation of fatty amides. The detection of oleamide and erucamide in the reference samples and the detection of methyl ricinoleate at GC retention time of 26.573 minutes in the castor oil product sample validates the GC-MS analysis and confirms the functionality and applicability of this novel method of synthesis.
\end{abstract}

Keywords: Fatty Acids, Fatty Amides, Fatty Esters, Green Process, Synthetic Method, Gas Chromatogram, Mass Spectra

\section{Introduction}

\subsection{Relevance of Fatty Amides}

Fatty amides, like many other nitrogen derivatives of fatty acids (amines, amino acids, nitriles, etc), are of economic significance [1]. They have a wide range of applications based upon their physical properties, which is a function of their molecular structure.

Long chain saturated amides, such as stearamide, behenamide and the amides from saturated fatty acids or the mixed arachidamide-behenamide, are used in the production 
of zelan or velan type water repellent (waterproofing) for textiles. The shorter chain saturated amide mixture obtained from coconut oil fatty acids is used as a foam stabilizer in synthetic detergent formulations [2]. The unsaturated oleamide is used as a slip and anti-block agent in polyethylene and polypropylene [3,4]. The simple amides are recommended as mutual solvents in the blending of waxes and plastics. They serve as thickening agents for paints and varnishes and in printing inks [5]. These amides are effective dye solubilizers in wax formulations and are especially useful in carbon paper manufacture. Some other uses of amides include fusible ceramic coatings, protective films and rubber compounding. They are also used as lubricating additives in power transmission units [2]. The more complex substituted fatty acid amides are primarily surface-active agents, which are used as emulsifiers, detergents, in cosmetics and in lubricants $[6,7]$. Medicinally, fatty amides are used in the manufacture of drugs for the treatment of tuberculosis, as anti-hypertensive agents, and as anticonvulsants $[6,8,9]$. They are useful in the treatment or prevention of metabolic disorders, respiratory diseases, neurodegenerative diseases, such as Parkinson's disease and Alzheimer's disease [7]. They are also important in treating a variety of cancers [7]. It is now well established that fatty acyl amides modulate several physiological processes, including pain sensitivity, reproduction, immune function and vascular tone among others $[10,11]$.

Anandamide is said to have important anti-inflammatory and anti-cancer properties and affects the cardiovascular system by inducing profound decreases in blood pressure and heart rate [12-16].

Oleoylethaolamide is an endogenous regulator of food intake, and could have some potential as an anti-obesity drug [7]. Oleamide (cis-9, 10-Octadecenamide) is a primary fatty acid amide which was first isolated from the cerebrospinal fluid of sleep-deprived cats, and has been characterized and identified as the signaling molecule responsible for causing sleep [17]. For example, it induces physiological sleep when injected into the brain of rats. Although other fatty acid primary amides in addition to oleamide are present naturally in the cerebrospinal fluids of animals, none exhibits similar physiological activity [7]

Fatty amides are widely produced from the reaction of $\mathrm{NH}_{3}$ with fatty acids at high temperatures $\left(100-240^{\circ} \mathrm{C}\right)$ and high pressures, with long reaction times of 3-72 hours with the use of catalysts which may be toxic $[6,18]$. Fatty acids are however, derived from fatty esters - vegetable oils (glycerides) which are available in abundance and are renewable but are never used directly in this synthesis without first stripping them to fatty acids because of poor product yield and harsh reaction conditions. This two-step process of synthesis has economic and environmental implications.

Indices such as environmental impacts, energy conservation, waste reduction and hazardous substance reduction or elimination are important factors in the design of chemical products and processes. These metrics are of high relevance in the $21^{\text {st }}$ century because of a growing need for environmental protection and better health for the populace. To this end, we had reported a novel green method for fatty amide synthesis from groundnut oil [6] with conversions as high as $80 \%$ at $50^{\circ} \mathrm{C}$ in 60 minutes in the absence of a catalyst. The traditional methods require a range of reagents, a temperature range of $100-240^{\circ} \mathrm{C}$ and a reaction time of $3-$ 72 hours in the presence of catalysts.

The fatty amides market is growing rapidly due to factors such as the rising trend in the use of organic additives in many industries (e.g. the packaging industry) and growing awareness about the negative impact of plastics and petroleum-based products on the environment. This has resulted in the preference of bio-based raw materials over petrochemicals [19] therefore, more sustainable and cost effective, environmentally friendly ways of production of fatty amides will help to promote this market target. Hence our interest in evaluating the applicability of the single step method reported by us.

\section{Present Study}

The aim of the current study is to: test the viability of the one-step method of synthesizing fatty amides directly from fatty esters using a culinary and a non - culinary fatty ester, peanut and castor oils, respectively.

\subsection{Fatty Acids of the Esters Used in the Synthesis}

Table 1. Fatty acid composition of peanut oil and castor oil [20-25].

\begin{tabular}{lll}
\hline Oils & Peanut & Castor \\
\hline Fatty acid & Percentage (\%) & \\
\hline Myristic (14:0) & 0.33 & - \\
Palmitic (16:0) & 9.37 & 0.7 \\
Palmitoleic & 0.37 & - \\
Stearic (18:0) & 4.00 & 0.9 \\
Oleic (18:1) & 55.10 & 2.8 \\
Linoleic (18:2) & 26.53 & 4.4 \\
Linolenic (18:3) & 0.23 & 0.2 \\
Ricinoleic; C18:1 $\omega$ OH & -- & 90.2 \\
Arachidic (20:0) & 1.93 & - \\
Erucic acid (22:1) & -- & -- \\
Gadoleic & 1.23 & - \\
Behenic & 3.47 & -- \\
\hline
\end{tabular}




\begin{tabular}{lll}
\hline Oils & Peanut & Castor \\
\hline Lauric acid (12:0) & - & -- \\
Total SFAs & 18 & 1.6 \\
Total UFAs & 82 & 97.6 \\
\hline
\end{tabular}

SFA (Saturated fatty acid) UFA (Unsaturated fatty acid).

\subsection{Predominant Fatty Acids of the Fatty Esters and their Amides}

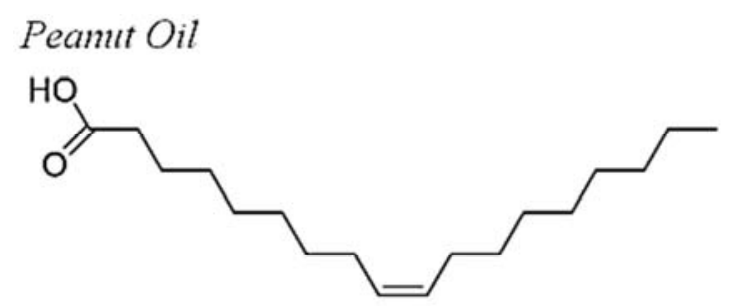

Oleic Acid - C18



9-Octadecenamide (Oleamide)

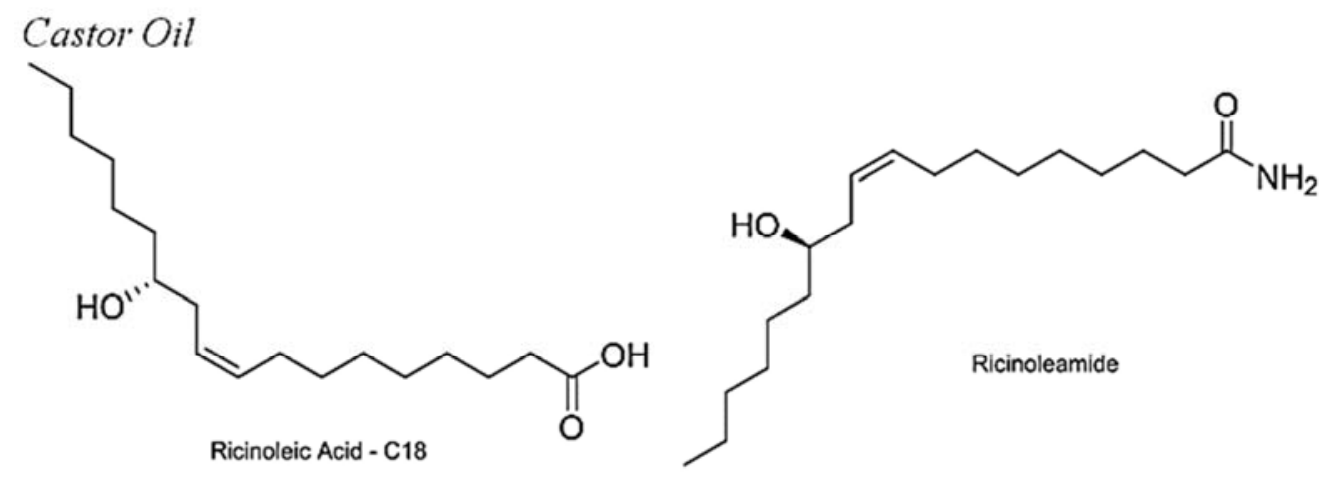

Figure 1. Chemical structures of the fatty acids and their corresponding amides.

\section{Experimental Method}

\subsection{Materials}

Peanut oil, acetone, $\mathrm{NaOH}, \mathrm{NH}_{4} \mathrm{Cl}, \mathrm{NaCl}$, Methanol, Butchi Rotavapor RII (Rotavap). Perkin Elmer Spectrum 100 FT-IR.

\subsection{Procedure}

(The method of synthesis reported by Abel-Anyebe et al, 2013 was modified to allow for better temperature control).

The evaporation flask of the Rotavap was charged with $3.84 \mathrm{~g}$ of oil and $15 \mathrm{~mL}$ of acetone. The reactor was heated to the required temperature $\left(50^{\circ} \mathrm{C}\right), 0.5 \mathrm{~g}$ of finely crushed pellets of $\mathrm{NaOH}$ was added and the mixture was left to rotate at rotor speed of 6rpm for 10 minutes for pre-stripping of the oil. $1.0 \mathrm{~g}$ of $\mathrm{NH}_{4} \mathrm{Cl}$ was introduced and, while maintaining the same rotation speed, the reaction was run for 60 minutes.

The reaction mixture was left to cool and thereafter shaken with $1 \mathrm{M}$ aqueous solution of $\mathrm{NaCl}$ to salt-out the solid product which was filtered off, washed in acetone, dried and weighed. The filtrate contained both acetone and unreacted oil. This was heated to dryness in an oven and the weight of the unreacted oil was determined.

The above procedure was carried out for castor oil.

Products obtained from the reactions were subjected to IR analysis.

\subsection{GC-MS Analysis}

\subsubsection{Materials}

Product samples (from peanut and castor oils); Reference samples (external standards): oleamide and erucamide (from Sigma Aldrich); methanol; acetonitrile;

GC-MS spectrometer - Agilent 5973N.

\subsubsection{Procedure}

Three solutions of each product and reference sample were prepared $-1 \mathrm{mg} / \mathrm{mL}$ (A), $0.1 \mathrm{mg} / \mathrm{mL}$ (B) and $0.01 \mathrm{mg} / \mathrm{mL}$ (C), filtered into GC vials, capped, labelled and submitted for GC-MS analysis.

\subsubsection{GC-MS Conditions}

GC-MS analysis was conducted using HP 5MS column. Column oven temperature was initially $50^{\circ} \mathrm{C}$, held for $3 \mathrm{mins}$ and programmed to a maximum of $325^{\circ} \mathrm{C}$ at an increase rate of $15^{\circ} \mathrm{C} / \mathrm{min}$. Total run time was $49.50 \mathrm{~min}$. The temperature of the injector port was $250^{\circ} \mathrm{C}$ in splitless mode with an injection volume of $1 \mu \mathrm{L}$. Carrier gas (helium) flow rate was $5 \mathrm{~mL} / \mathrm{min}$. Mass spectra scanning range was $40-650 \mathrm{~m} / \mathrm{z}$

\section{Results and Discussion}

Conversions of 83 and $79 \%$ were recorded for the reactions involving peanut and castor oils, respectively. 


\subsection{FT-IR Analysis: Peaks of Interest}

For the determination of the formation of fatty amides, the following IR absorption bands can be used to characterize and quantify such formation $[31,32]$ :

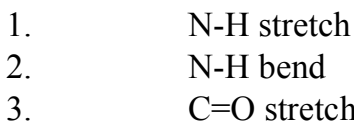

$$
\begin{aligned}
& 3100-3500 \mathrm{~cm}^{-1} \\
& 1550-1640 \mathrm{~cm}^{-1} \\
& 1670-1820 \mathrm{~cm}^{-1}
\end{aligned}
$$

If fatty acids are formed, the following absorption bands are expected:

$\begin{array}{lll}1 & \mathrm{C}=\mathrm{O} \text { stretch } & 1700-1725 \mathrm{~cm}^{-1} \text { strong } \\ 2 & \mathrm{O}-\mathrm{H} \text { stretch } & 2500-3300 \mathrm{~cm}^{-1} \text { strong, very broad } \\ 3 & \text { C-O stretch } & 1210-1320 \mathrm{~cm}^{-1} \text { strong }\end{array}$

Esters exhibit the following absorption peaks [32]:

1. $\mathrm{C}=\mathrm{O}$ stretch aliphatic $1750-1735 \mathrm{~cm}^{-1} ; \alpha, \beta$ unsaturated $1730-1715 \mathrm{~cm}^{-1}$

2. C-O stretch $1300-1000 \mathrm{~cm}^{-1}$

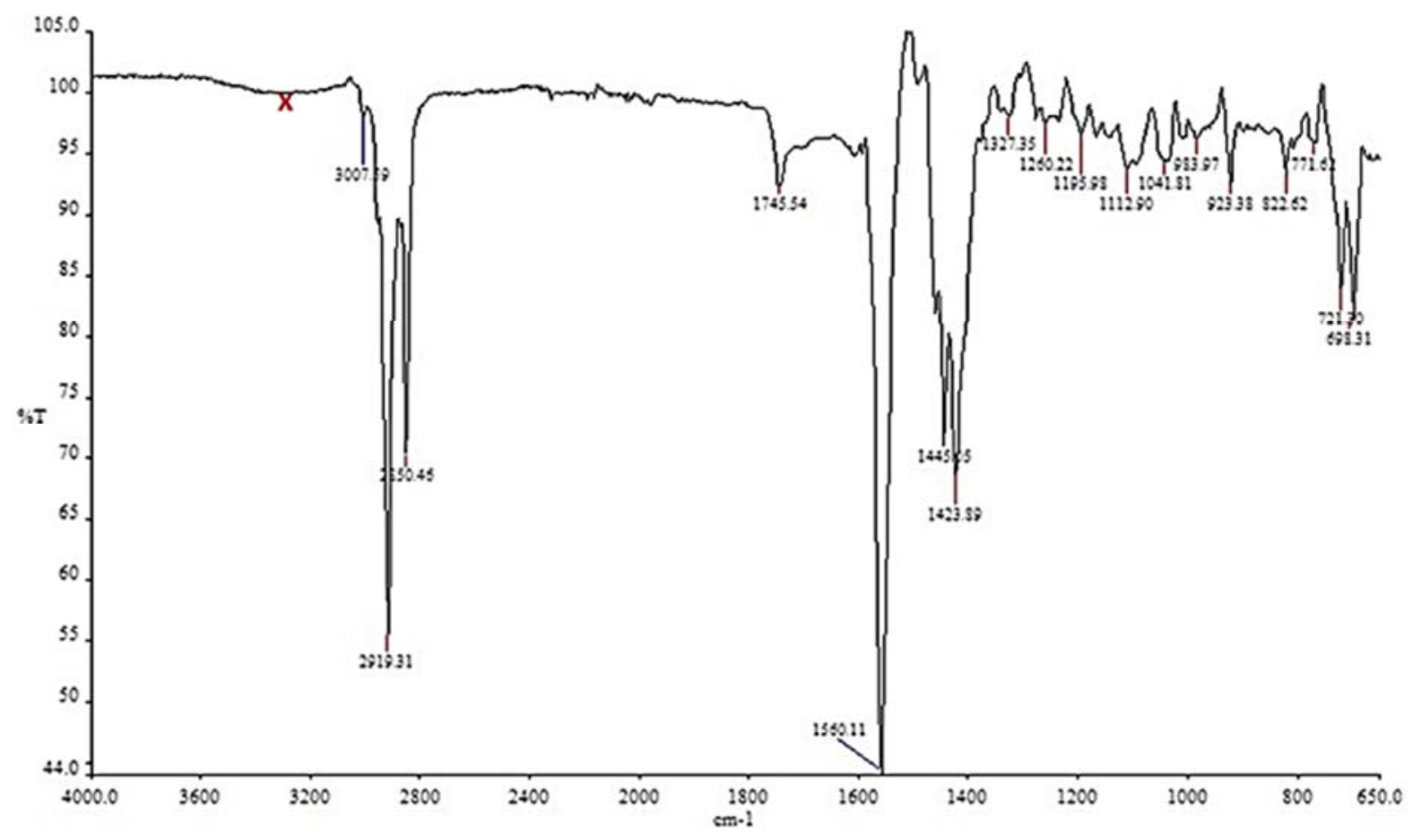

Figure 2. Peanut Oil Product at $60^{\circ} \mathrm{C}$.

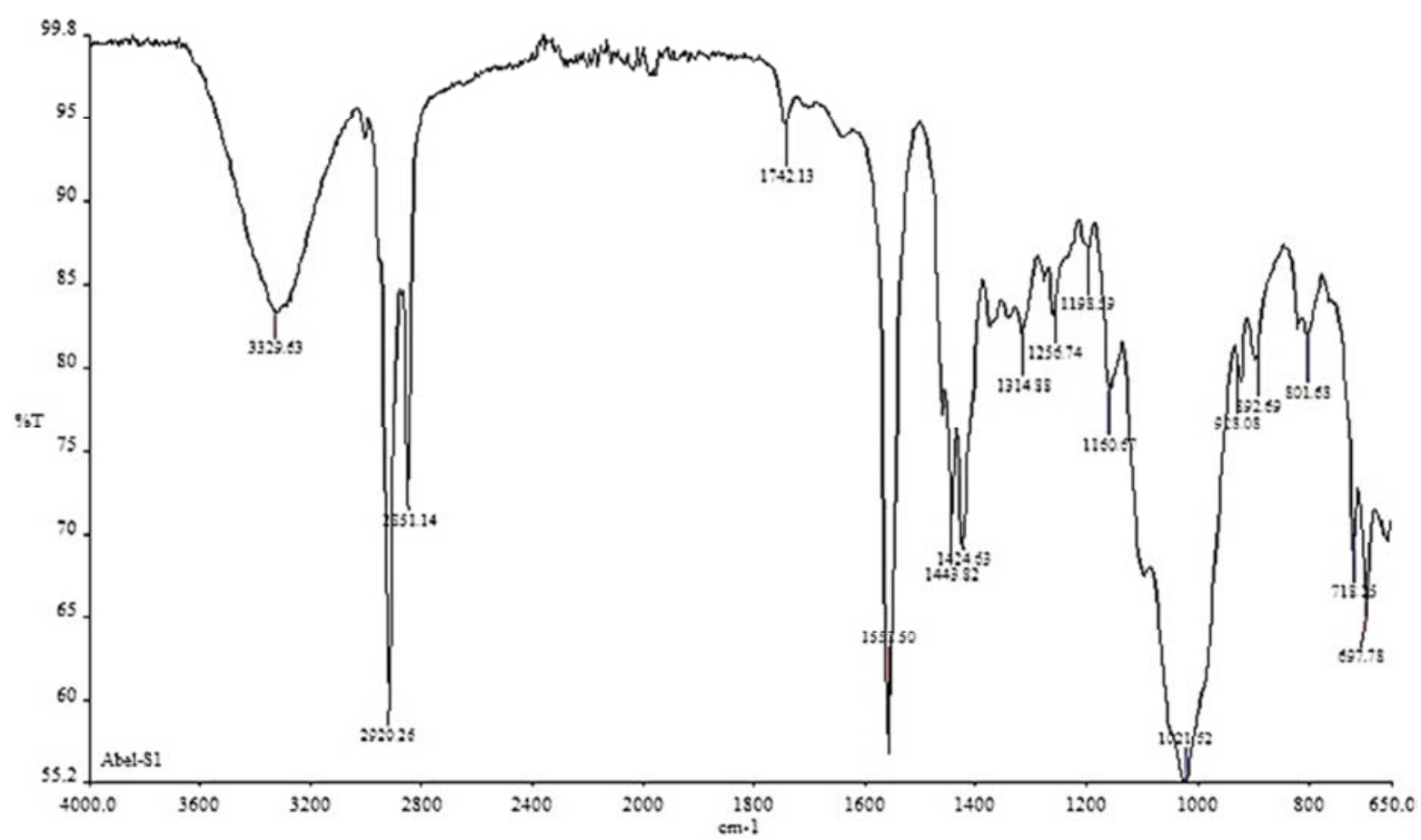

Figure 3. Peanut Oil Product at $50^{\circ} \mathrm{C}$. 


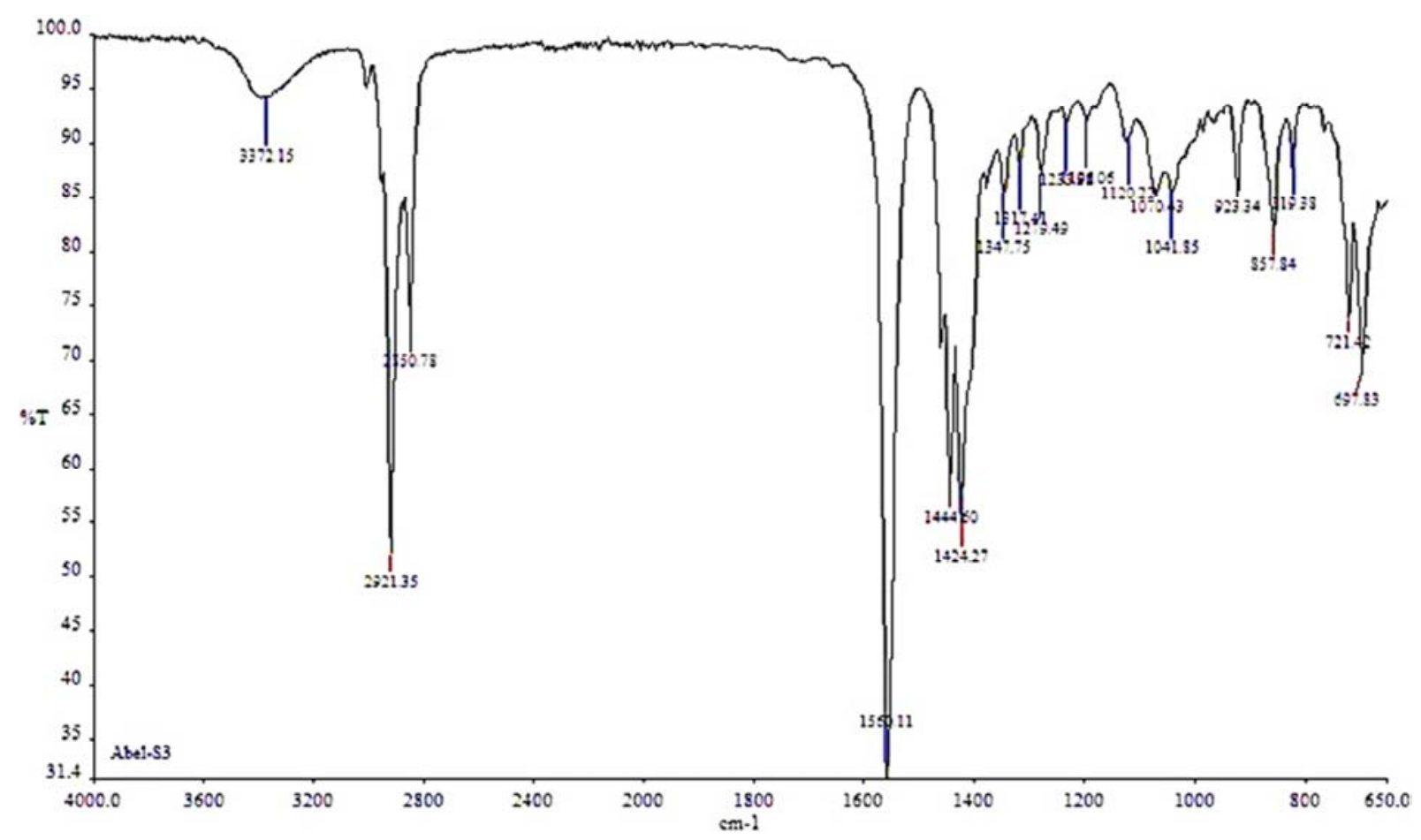

Figure 4. Castor Oil Product at $50^{\circ} \mathrm{C}$.

Figures 2 and 3 are the IR spectra of the products obtained from peanut oil at $60^{\circ} \mathrm{C}$ and $50^{\circ} \mathrm{C}$, respectively. Absorption bands appearing at $1742.13 \mathrm{~cm}^{-1}$ and $1560.11 \mathrm{~cm}^{-1}$ in Figure 2 are suggestive of the presence of either $-\mathrm{NH}_{2}$ or $-\mathrm{NH}_{4}$ groups (or both) ${ }^{6}$. The peak at $1742.13 \mathrm{~cm}^{-1}$ may also be due to the presence of ester in the product sample. However, there is no obvious peak in the $3300-3500 \mathrm{~cm}^{-1}$ region marked $\mathrm{x}$, but the line is not completely horizontal; there is a small deep which is an indication of a weak peak. The band at $3329.63 \mathrm{~cm}^{-1}$ in Figure 3 is a confirmation of the weak peak seen in Figure 2. We previously reported the temperature dependence of the peanut oil reaction and the optimum temperature was $50^{\circ} \mathrm{C}^{6}$. This finding is further confirmed by the appearance of this strong peak which was weak at a reaction temperature of $60^{\circ} \mathrm{C}$. In conjunction with the absorption peaks at $1744.66 \mathrm{~cm}^{-1}$ and $1558.50 \mathrm{~cm}^{-1}$, there is clear evidence of the formation of amide.

Figure 4 is the IR spectrum of the castor oil product. The spectrum shows no presence of the carbonyl group which should be seen at $1670-1820 \mathrm{~cm}^{-1}$. The broadness of the absorption band at $3384.62 \mathrm{~cm}^{-1}$ is probably due to the presence of $-\mathrm{OH}$ in the predominant fatty acid of castor oil, ricinoleic acid. This is the region characteristic of $\mathrm{N}-\mathrm{H}$ stretching, and a sharp peak at $1560.11 \mathrm{~cm}^{-1}$ is probably due to $\mathrm{N}-\mathrm{H}$ bending. These two peaks are strongly indicative of the formation of amide.

The absence of strong absorption peaks in $1210-1320 \mathrm{~cm}^{-1}$ region signifies the absence (no formation) of fatty acid in any of the product samples.

\subsection{GC-MS Analysis}

GC-MS analysis was carried out for the peanut oil products obtained at 50 and $60^{\circ} \mathrm{C}$; and for the castor oil product obtained at $50^{\circ} \mathrm{C}$, as well as for the two reference samples, oleamide and erucamide. Qualitative GC-MS reports revealed the presence of 9-octadecenamide (oleamide) and hexadecanamide (palmitamide) at retention times 27.76 and 23.90 minutes, respectively for all samples including the reference samples.

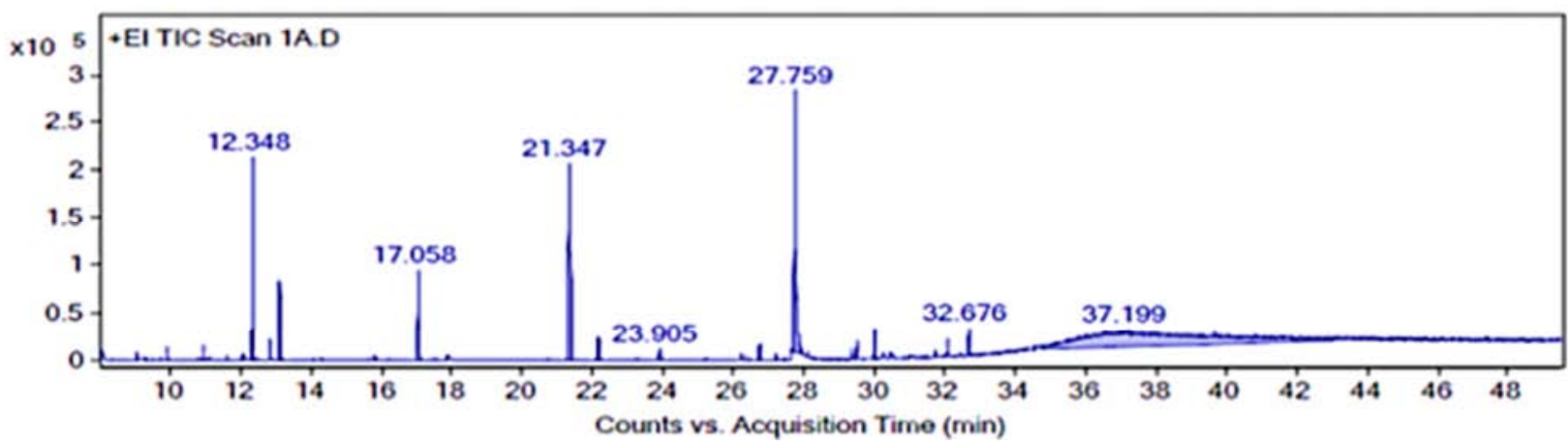

Figure 5. Gas chromatogram of sample 1 - Peanut oil product at $50^{\circ} \mathrm{C}$. 


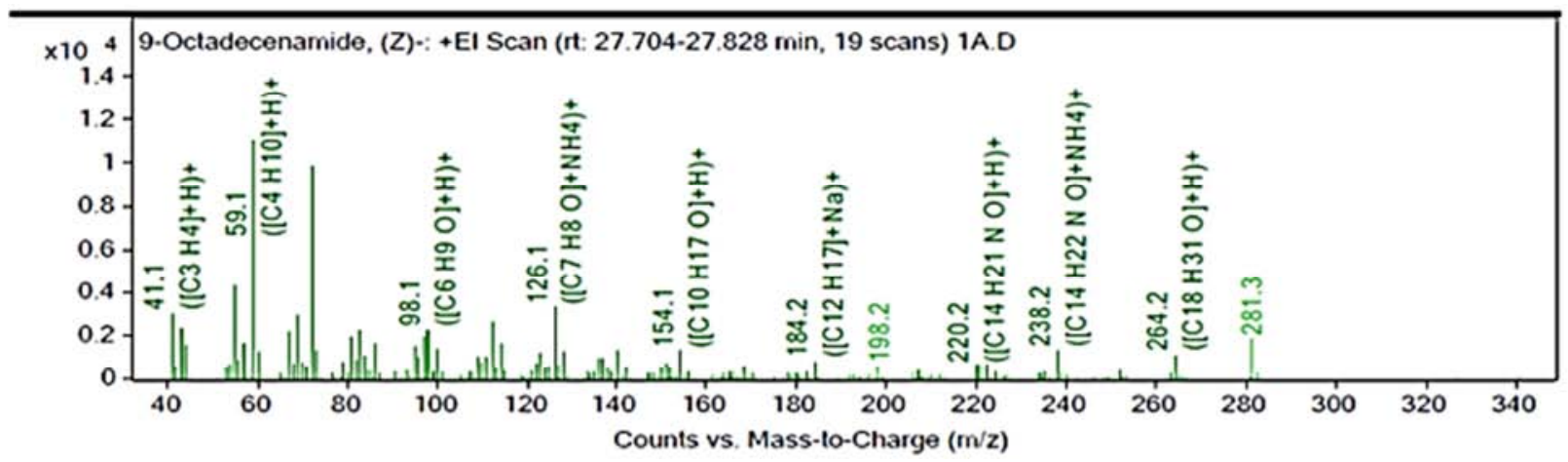

Figure 6. Mass spectrum of sample 1.

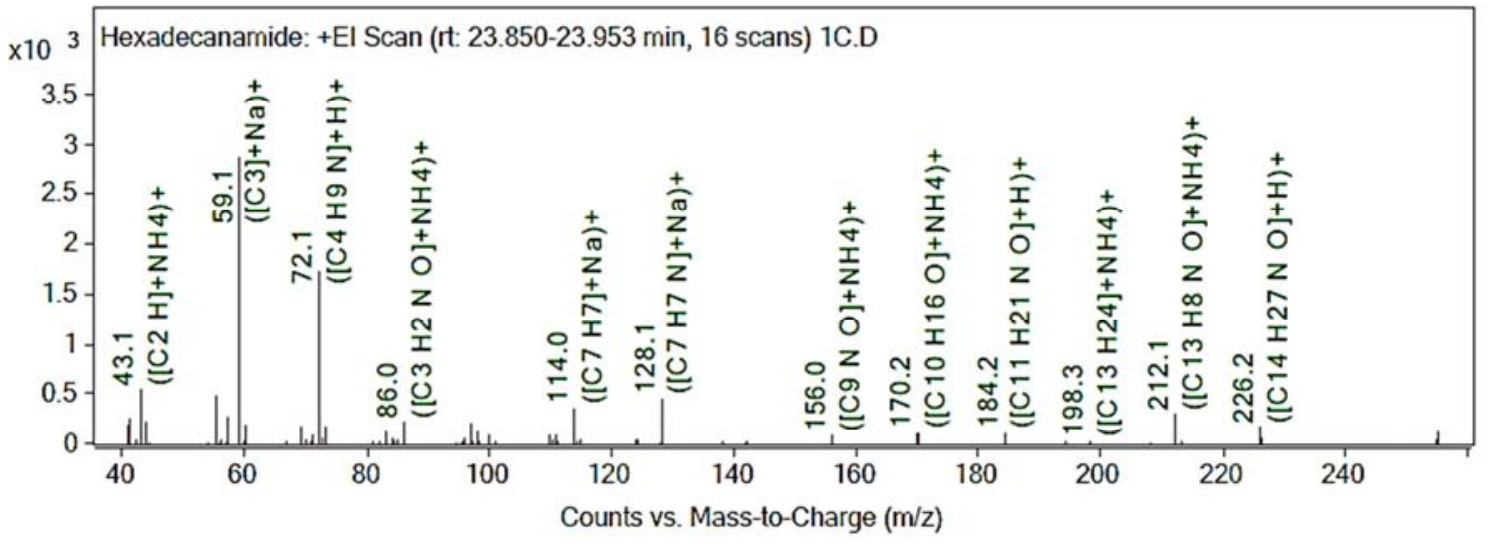

Figure 7. Mass spectrum of sample 1.

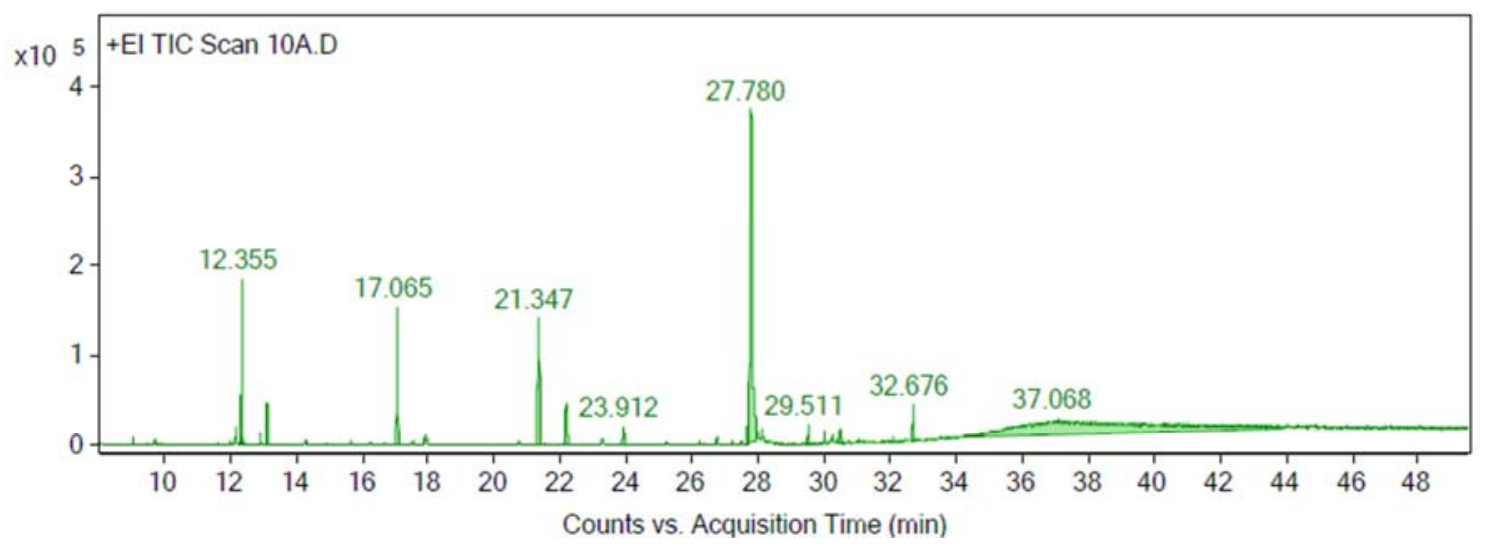

Figure 8. Gas chromatogram of sample 10 - Peanut oil product at $60^{\circ} \mathrm{C}$.

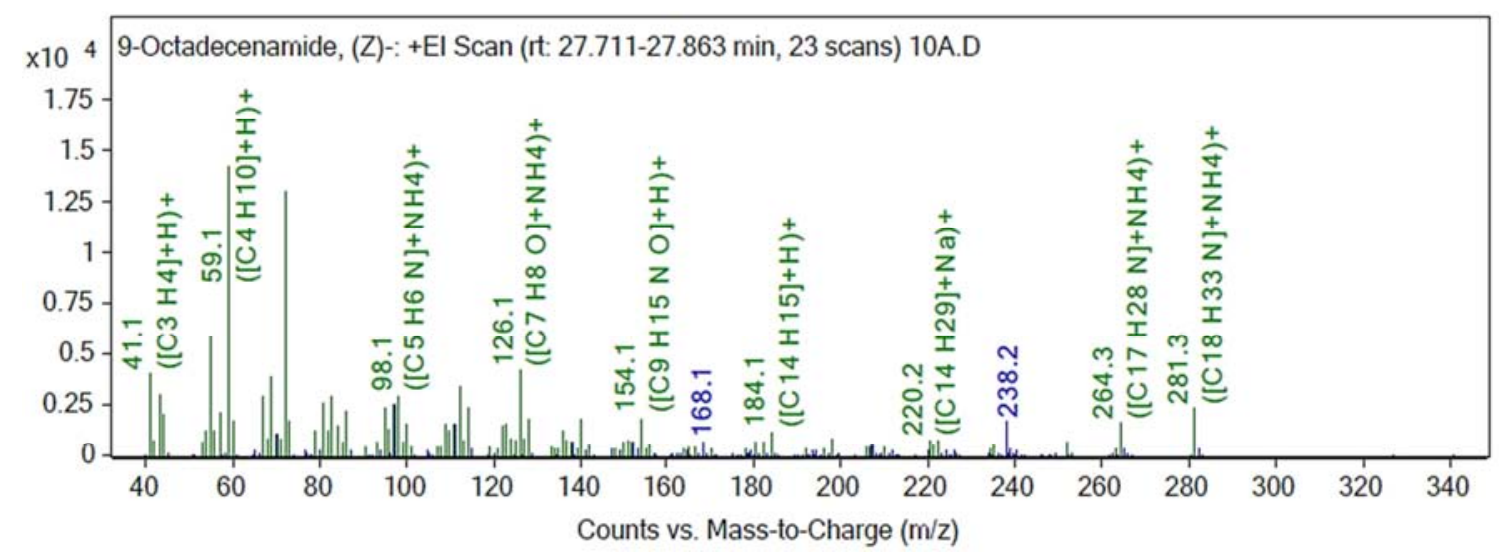

Figure 9. Mass spectrum of sample 10. 


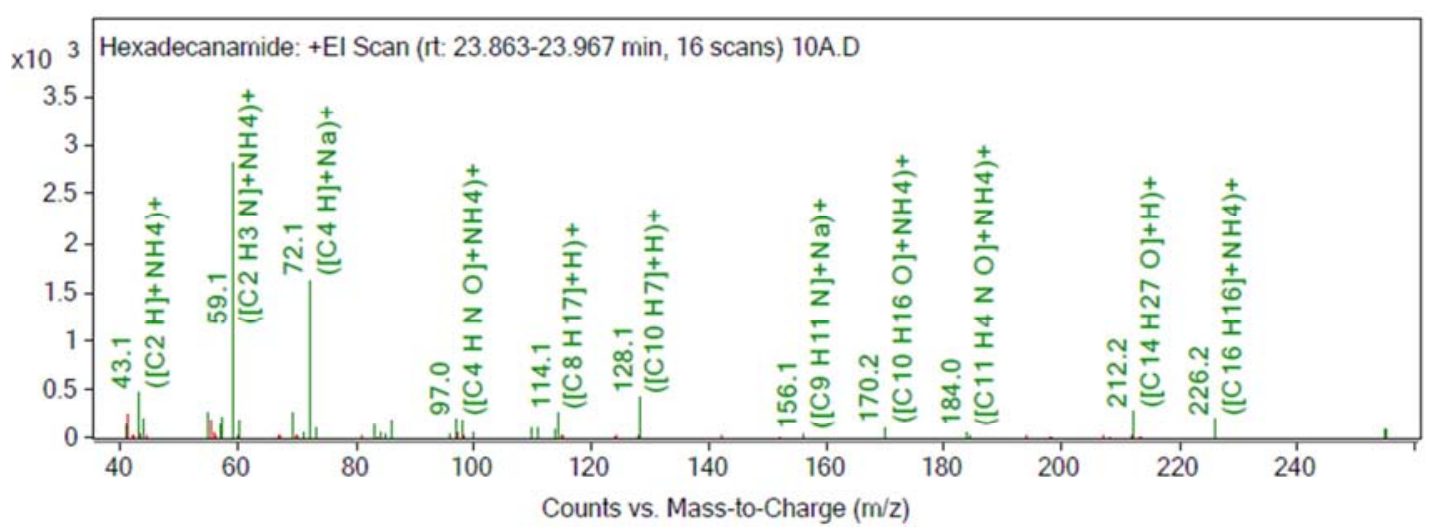

Figure 10. Mass spectrum of sample 10

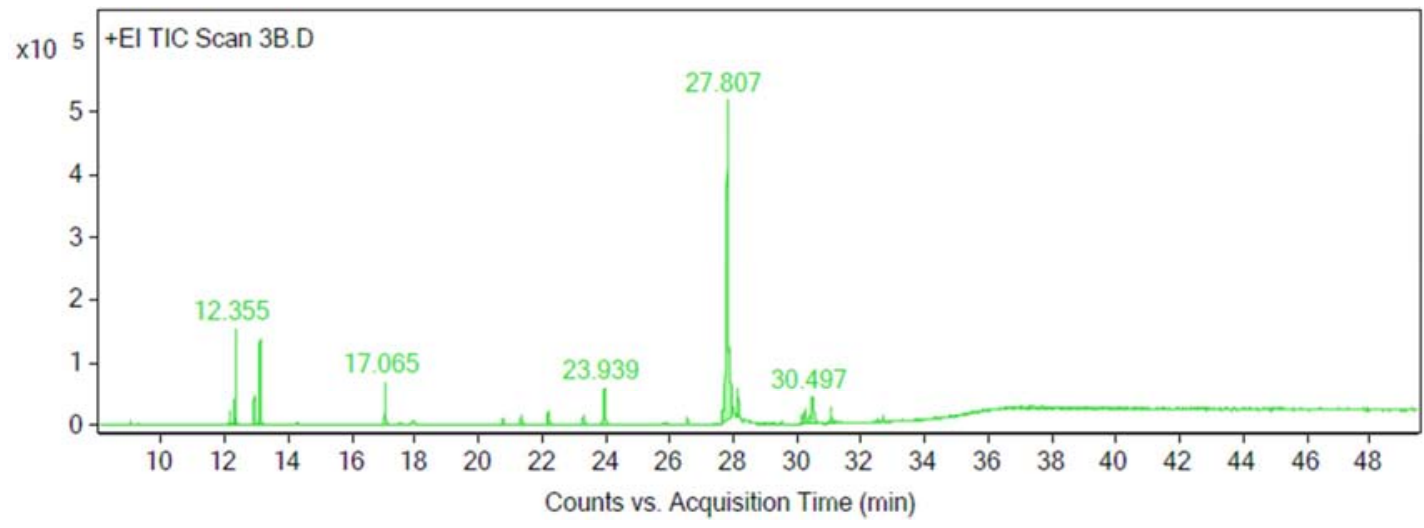

Figure 11. Gas chromatogram of sample 3 - castor oil product at $50^{\circ} \mathrm{C}$.

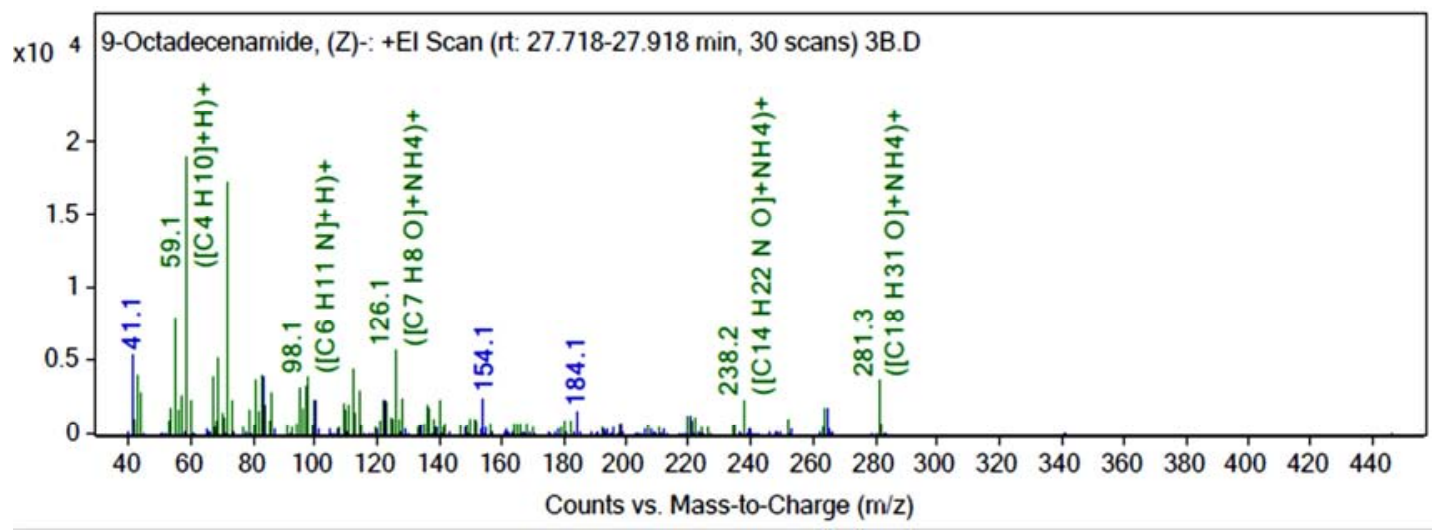

Figure 12. Mass spectrum of sample 3.



Figure 13. Mass spectrum of sample 3. 


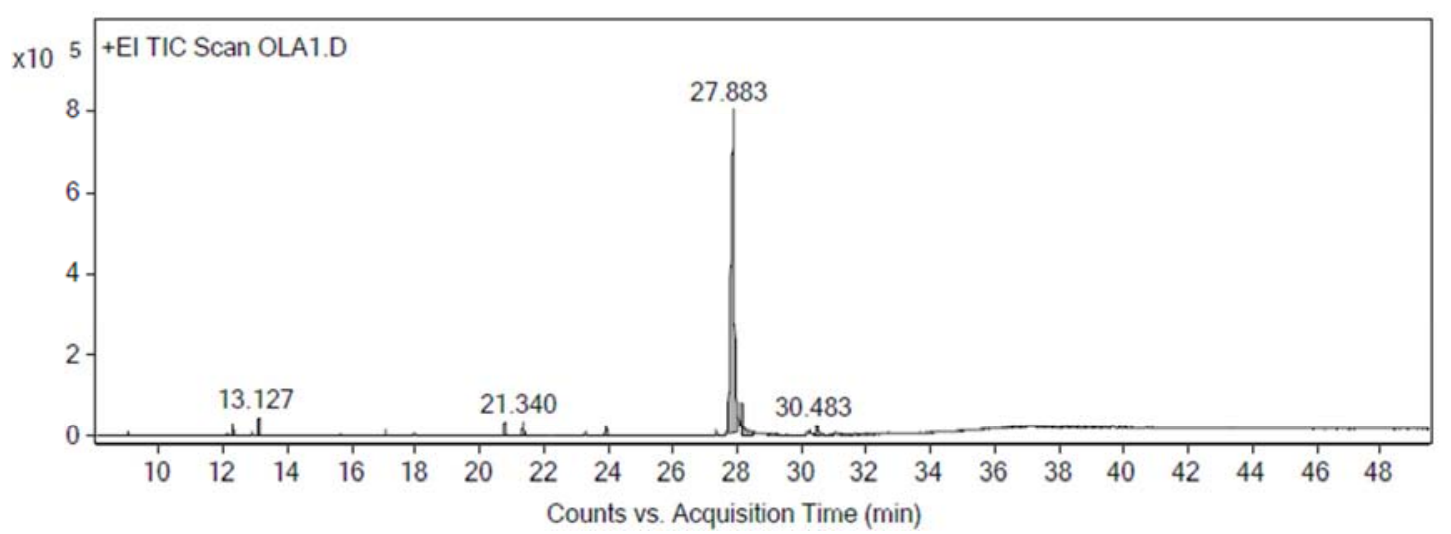

Figure 14. Gas chromatogram of reference sample 1 -Oleamide.

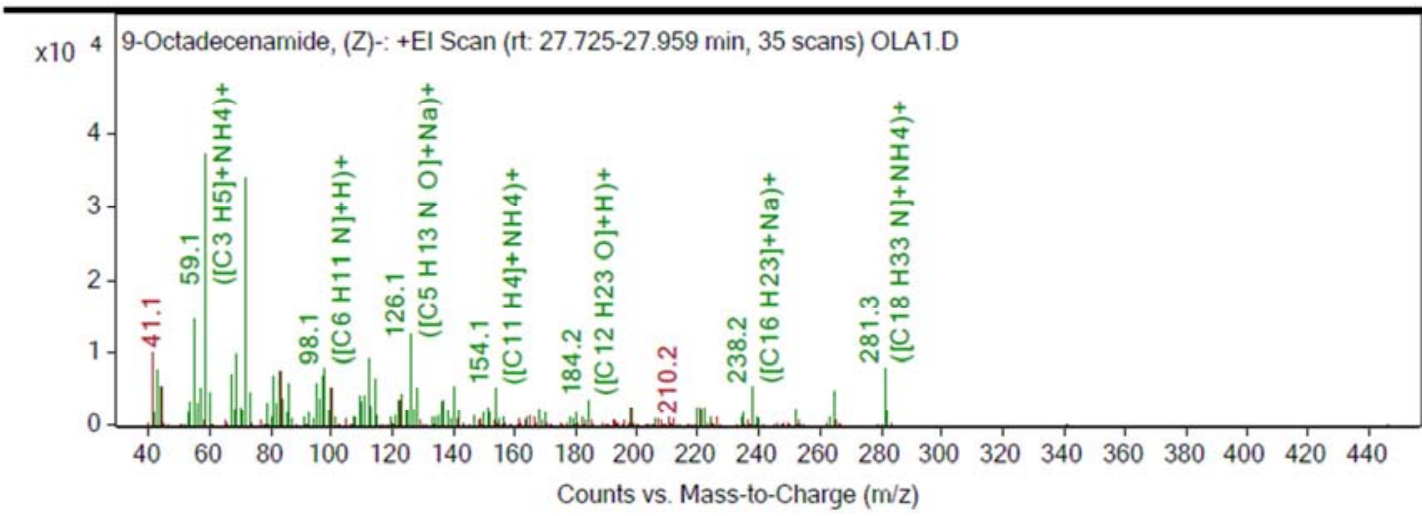

Figure 15. Mass spectrum of reference sample 1 - Oleamide.

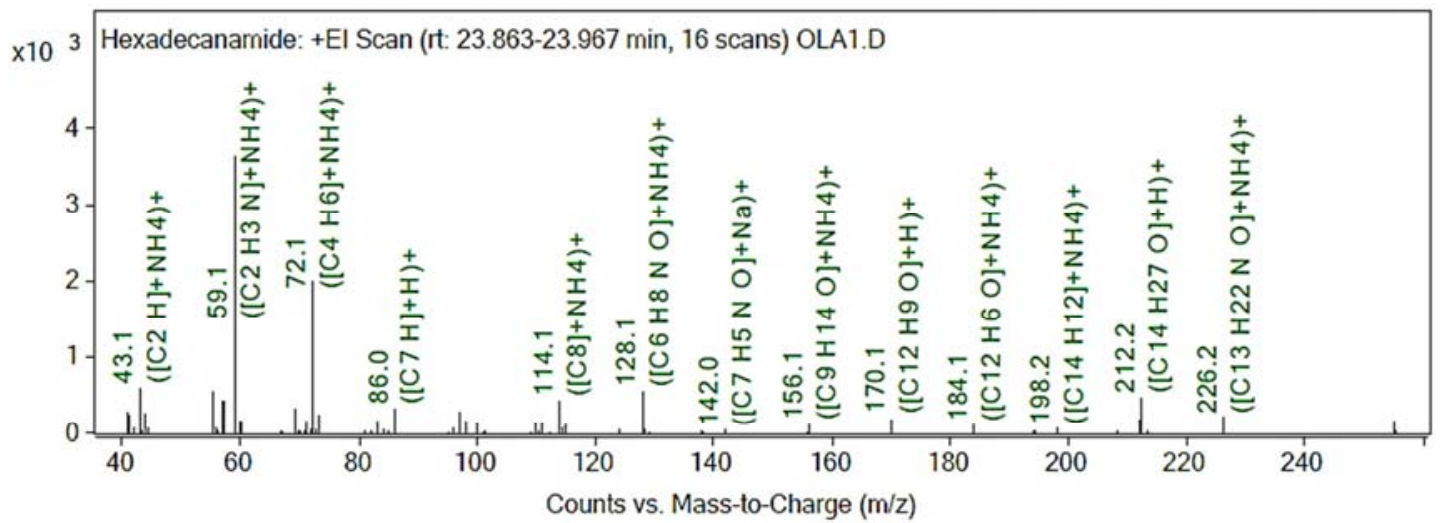

Figure 16. Mass spectrum of reference sample 1.

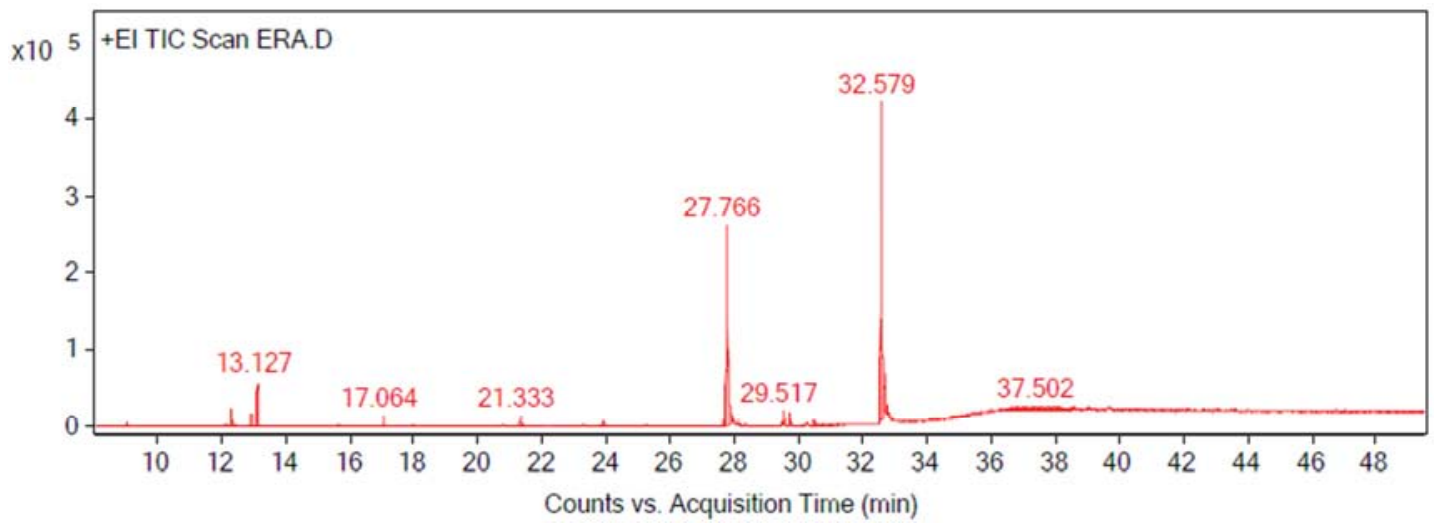

Figure 17. Gas chromatogram of reference sample 2 - Erucamide. 


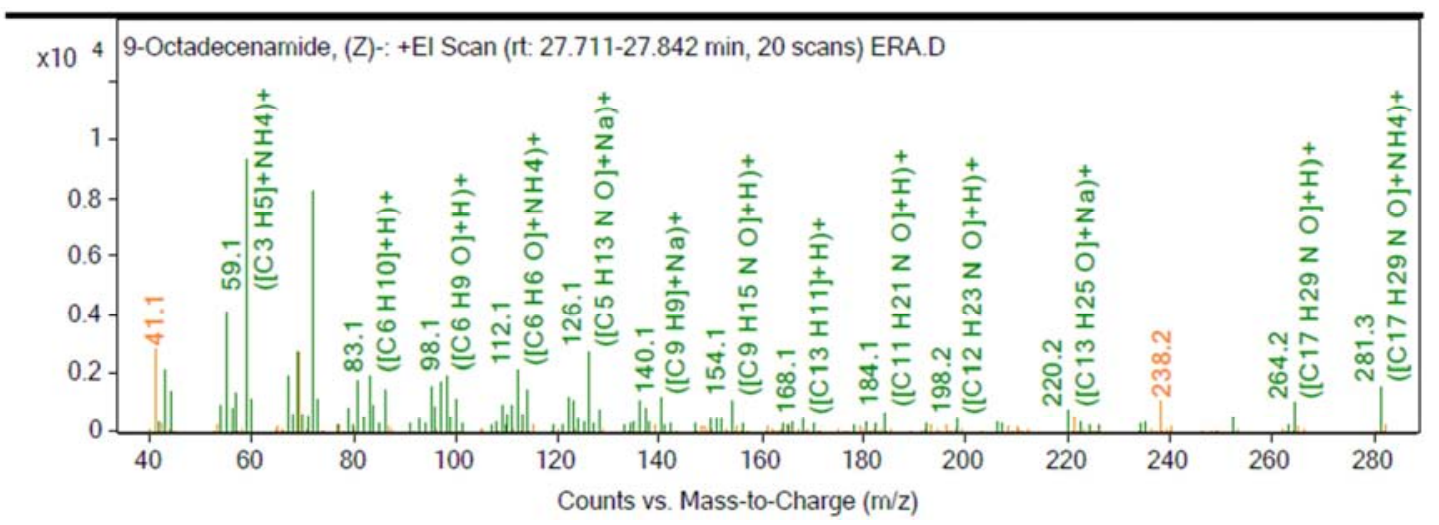

Figure 18. Mass spectrum of reference sample 2.

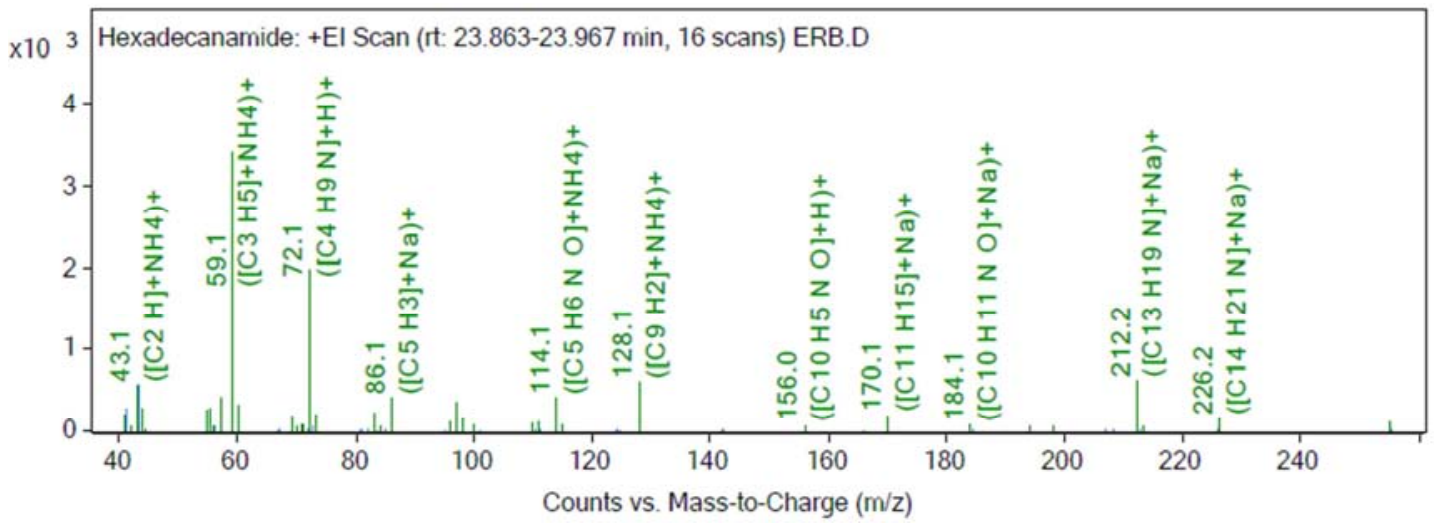

Figure 19. Mass spectrum of reference sample 2.

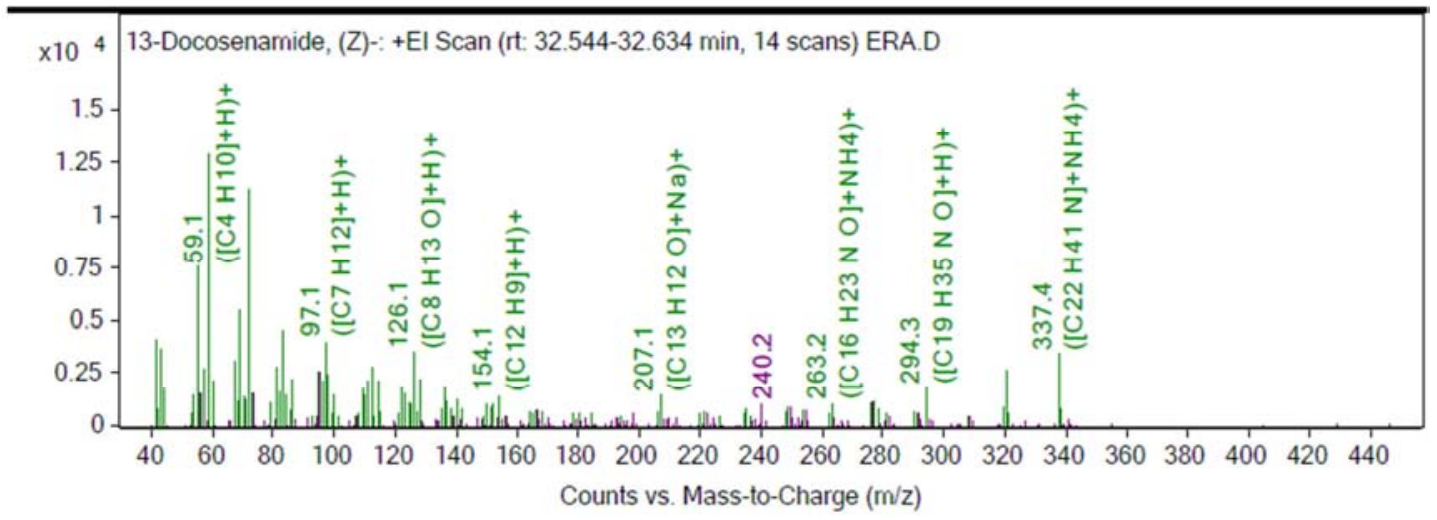

Figure 20. Mass spectrum of reference sample 2.

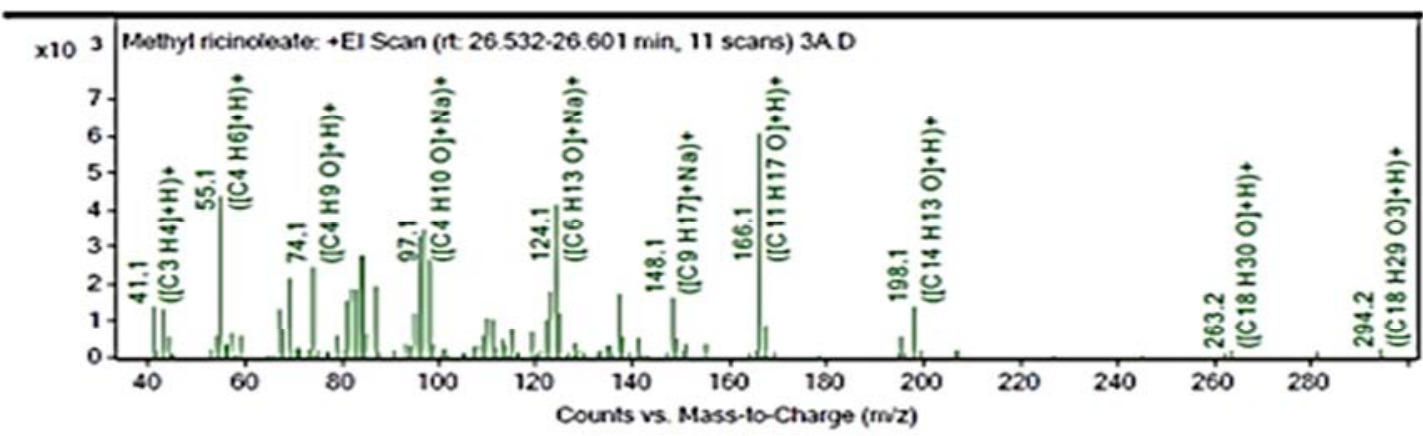

Figure 21. Mass spectrum of sample 3.

Figures 5, 8, 11, 14 and 17 are gas chromatograms of the product samples and reference samples showing GC peaks at 
27.76 and 23.90 minutes representing 9-octadecenamide (oleamide) and hexadecanamide (palmitamide) respectively. Figures $6,7,9,10,12,13,15,16,18$ and 19 are mass spectra of product samples and reference samples confirming the formation of the two fatty amides.

Figure 21 is the mass spectrum of the castor oil product sample confirming the detection of methyl ricinoleate shown at $\mathrm{GC}$ retention time of 26.573 minutes in figure 5. This is a derivative of ricinoleic acid which is the predominant fatty acid in castor oil but absent in peanut oil (Table 1). This peak is absent in the gas chromatograms of the peanut oil products. As seen from the IR spectra of the product samples, Figures 2, 3 and 4, non-amides such as esters of fatty acids present in the fatty esters were also detected in the mass spectra of the product samples.

\section{Conclusion}

We have successfully used a one-step green process in the production of fatty amides from peanut and castor oils without chemical catalysis and at a low temperature of $50^{\circ} \mathrm{C}$ in a reaction time of 60 minutes. This method of synthesis is green and novel and should be viable for synthesis from different types of fatty esters. Quantitative analysis for the determination of the amount of amide formed in each case is underway and it is envisaged that this one-step process can be scaled-up for industrial scale synthesis of fatty amides from different fatty esters and to be achievable on multi-gram scale levels. In order to sustain edible sources of fatty esters for humans, it is recommended that more fatty esters be studied for comparative product yield and subsequent identification of non-culinary fatty esters that will generate the best product yields and be best suited for fatty amide production.

\section{Conflicts of Interest}

The authors declare that they have no competing interests.

\section{Acknowledgements}

We are grateful to the Chemistry department of Howard University for the IR spectra of the samples.

\section{References}

[1] Harwood, H. J. Nitrogen-containing derivatives of the fatty acids. Journal of the American Oil Chemists Society 1954, Volume 31, Issue 11, pp 559-564.

[2] Abel-Anyebe, O. Fatty Amide Formation by Direct Vegetable Oil Stripping. Doctoral Dissertation, University of Jos 2011.

[3] Getachew, P.; Getachew, M.; Joo, J.; Choi, Y. S.; Hwang, D. S.; Hong, Y. The Slip Agents Oleamide and Erucamide Reduce Biofouling by Marine Benthic Organisms (Diatoms, Biofilms and Abalones). Tox. and Env Health Sciences 20168 (5) 341-348.
[4] Mathew's Chemistry Blog Extraction of the slip-additives erucamide, behenamide and oleamide https://www.mjlphd.net/blog/extraction-of-the-slip-additiveserucamide-behenamide-and-oleamide.

[5] Jaeger, C. W.; Titterington, D. R.; Bui, L. V. US Patent 5,902,841, Google Patents, 1/jo400509n.

[6] Abel-Anyebe, O.; Ekpenyong, K. I.; Eseyin, A. Int. J. Chem, 2013, 5, 1, 80-86.

[7] Milne, J. C.; Jirousek, R.; Bemis, J. E.; Vu, C. B.; Ting, A. Patents no US20130059801, 2013.

[8] M. Vishe, M.; J. N. Johnston, J. N.; The Inverted Ketene Synthon: A Double Umpolung Approach to Enantioselective B2,3-Amino Amide Synthesis Chem. Sci., 2019, Advance Article DOI: $10.1039 / \mathrm{c} 8 \mathrm{sc} 04330 \mathrm{~b}$.

[9] Tremblay, H.; St-Georges, C.; Legault, M. A.; Morin, C.; Fortin, S.; Marsault, E.; One-pot Synthesis of Polyunsaturated Fatty Acid Amides with Anti-proliferative Properties, Bioorganic \& Med. Chem. Letts., 2014, 24, 24, 5635-5638.

[10] Viveros, M.; Marco, E.; Llorente, R.; L'opez-Gallardo, M.; Endocannabinoid System and Synaptic Plasticity: Implications for Emotional Responses Neural Plasticity, 2007, 52908.

[11] Tan, B.; Bradshaw, H. B.; Rimmerman, N.; Srinivasan, H.; Yu, Y. W.; Krey, J. F.; Monn, M. F.; Chen, J. S.; Hu, S. S.; Pickens, S. R.; Walker, J. M.). Targeted Lipidomics: Discovery of New Fatty Acyl Amides. AAPSJ, 2006, 8, 3, 54.

[12] Christie, W. W.; Anandamide, Oleamide and other Fatty Amides: Structure, Occurrence, Biology and Analysis Lipid Library, http://www.lipidlibrary.co.uk.

[13] http://www.en.wikipedia.org/wiki/Anandamide.

[14] Hanus, L.; Gopher, A.; Almong S.; Mechoulam, R.; Two New Unsaturated Fatty Acid Ethanolamides in Brain that Bind to the Cannabinoid Receptor J. Med. Chem., 1993, 36: 3032-3034.

[15] Kunos, G.; Varga, K.; Wagner, J.; Ellis, E. F.; Sanyai, A. Cardiovascular Uses of Cannabinoid Compounds. US Patent 5939429.

[16] Brown University News Services, 11th October, 1999.

[17] Hedlund, P. B.; Carson, M. J.; Sutcliffe, J. G.; Thomas, E. A.; Allosteric Regulation by Oleamide of the Binding Properties of 5-Hydroxytryptamine7 Receptors Biochem pharmacol, 1999, 58, 11, 1807-13.

[18] Hoong, S. S.; Ahmad, S.; Hassan, H. A. Process for the Production of Fatty Acid Amides. Grant publication number US7098351 B2Grant no US7098351 B2.

[19] Research and Markets Fatty amides: Global market report (2018-2022) forecast, April 132018.

[20] Orsavova, J.; Misurcova, L.; Ambrozova, J. V.; Vicha, R.; Mlcek, J. Fatty Acids Composition of Vegetable Oils and Its Contribution to Dietary Energy Intake and Dependence of Cardiovascular Mortality on Dietary Intake of Fatty Acids. Int. J. Mol. Sci. 201516 12871-12890 doi: 10.3390/ijms160612871.

[21] Mancini, A.; Imperlini, E.; Nigro, E.; Montagnese, C.; Daniele, A.; Orrù, S.; Buono, P. Biological and Nutritional Properties of Palm Oil and Palmitic Acid: Effects on Health Molecules $2015 \quad 20 \quad$ (9) 17339-17361 DOI: $10.3390 /$ molecules 200917339 . 
[22] Salimon, J.; Mohd Noor, D. A; Nazrizawati, A. T.; Mohd Firdaus, M. Y.; Noraishah, A.; Fatty acid composition and physicochemical properties of Malaysian castor bean ricinus communis L. seed oil Sains Malaysiana, 2010, 39, 5, 761-764.

[23] Özcan, M.; Seven, S.; Physical and Chemical Analysis and Fatty Acid Composition of Peanut, Peanut Oil and Peanut Butter From ÇOM and NC-7 Cultivars. Grasas y Aceites 2003 Vol. 54 (1) 12-18.

[24] Youngs, C. G.; Mallard, T. M.; Craig, B. M.; Sallans, H. R. Component Fatty Acids of Rapeseed Oil. Canadian J. Chem. $192129871-876$

[25] https://www.quirkyscience.com/olive-oil-peanut-oil/.

[26] https://www.thekitchn.com/whats-the-difference-betweencanola-and-rapeseed-206047.

[27] https://www.foodsafety.gov.mo/e/sense/detail.aspx?id=b70be5 cf-6b48-4a6c.
[28] www.erinnudi.com/2015/06/25/difference-between-canola-oiland-rapeseed-oil/.

[29] Schafer, M. G.; Ross, A. A.; Londo, J. P.; Burdick, C. A.; Lee, E. H.; Travers, S. E.; Van de Water, P. K.; Sagers, C. L. The Establishment of Genetically Engineered Canola Populations in the U.S. PLoS One 20116 (10) 25736. doi: 10.1371/journal.pone.0025736.

[30] Canola Council of Canada. Canola: The Myths Debunked https://www.canolacouncil.org.

[31] http://www2.ups.edu/faculty/hanson/Spectroscopy/IR/IRfrequ encies.html.

[32] https://www1.udel.edu/chem/fox/Chem333/Fall2013/.../Welco me.../IR\%20handout.pdf. 